\title{
Prognosis
}

\section{Review: the location of stroke is not associated with the risk of depression}

Carson AJ, MacHale S, Allen K, et al. Depression after stroke and lesion location: a systematic review. Lancet 2000 Jul 8;356:122-6.

QUESTIONS: Do patients with stroke have a higher risk of depression if they have left sided lesions rather than right sided lesions? Are left anterior lesions associated with a higher risk of depression than lesions in other sites of the brain?

Source of funding: Chest, Heart and Stroke, Scotland.

For correspondence. Dr A J Carson, Department of Psychiatry, University of Edinburgh, Royal Edinburgh Hospital Edinburgh EH10 $5 \mathrm{HF}$ UK. Fax +44 (0) 131 5376140 .

\section{Data sources}

Studies were identified by searching Medline (1966 to Aug 1999), BIDS ISI (1981 to Aug 1999), and PsycLIT (1960 to Aug 1999); scanning reference lists; and handsearching Journal of Neurology, Neurosurgery and Psychiatry; Stroke; British Journal of Psychiatry; American Journal of Psychiatry; Brain; and Cerebrovascular Diseases for 1975 to August 31, 1999.

\section{Study selection}

Studies in any language were selected if they included an assessment of depression in patients with strokes and attempted to relate the presence of depression to the site of the stroke lesion.

\section{Data extraction}

2 reviewers independently extracted data on the source of patients, exclusion criteria, method of diagnosing stroke, time between stroke and assessment of depression, assessment of lesion location, method of diagnosing depression, and independent masked ratings of key variables (depression and lesion location). Disagreements were resolved by a third reviewer

\section{Main results}

48 reports met the selection criteria. 35 studies reported dichotomous data for depression and were included in the meta-analysis. No overall association between location lesion and the presence of depression was seen (table). Heterogeneity existed among the studies but did not seem related to quality of study methods, restriction of analysis to patients with major depressive disorder, time between stroke and depression assessment, or exclusion of patients with aphasia. When the locations of lesions were compared (anterior, intermediate, and posterior), the relative risk of depression did not differ among the brain regions assessed (table).

\section{Conclusion}

In patients who have had a stroke, the risk of depression is not associated with hemisphere or location of stroke.
Associations between lesion location and risk of depression in patients who have had a stroke

\begin{tabular}{lll} 
Location of lesion & $\begin{array}{l}\text { Number of } \\
\text { studies }\end{array}$ & $\begin{array}{l}\text { Weighted relative risk } \\
\text { for depression }(95 \% \mathrm{Cl})^{*}\end{array}$ \\
Left $v$ right hemispheres & 35 & $0.95(0.8$ to 1.1$)$ \\
\hline Left anterior $v$ all other & 7 & $1.1(0.9$ to 1.4$)$ \\
\hline Left anterior $v$ right anterior & 7 & $1.1(0.8$ to 1.5$)$ \\
\hline Left intermediate $v$ right intermediate & 4 & $1.7(0.8$ to 3.7$)$ \\
\hline Left posterior $v$ right posterior & 5 & $0.8(0.4$ to 1.4$)$ \\
\hline All anterior $v$ all posterior & 5 & $1.1(0.7$ to 1.6$)$
\end{tabular}

*All weighted relative risks are not statistically significant.

\section{COMMENTARY}

This systematic review is timely given the continuing interest in this topic. The findings of Carson et al are similar to those in a recent narrative review on the same subject.

The review was well designed, and it separated out comparisons between broad laterality (right $v$ left) and specific location (left anterior $v$ other) of lesions. Another strength is the authors' preference for commenting on potential study biases rather than using a categorical classification of studies according to numerical quality scores. It also highlights the heterogeneity among studies, which is particularly noticeable for those involving inpatients, where considerable bias may exist in population characteristics, such as race. It is known, for example, that people of Afro-Caribbean origin have a poorer prognosis after stroke when compared with other racial groups. ${ }^{2}$ This review overcomes problems with heterogeneity, however, by taking this into account in the analysis; this diversity did not affect the findings substantially.

The findings have important implications for clinical practice. Since the flurry of interest in the relation between stroke lesion location and depression during the 1980s and early 1990s, the importance of left anterior lesions in the pathogenesis of depression has been (erroneously) over emphasised. It is clear that the presence of a left or anteriorly situated stroke lesion does not increase the risk of depression.

The review makes 2 other important points about studies examining depression and lesion location after stroke. Firstly, describing a "consecutive series" of patients may be misleading because little information may be available to assess how representative the sample is of the people eligible for recruitment into the study. Secondly, many studies appear to duplicate data on the same cohort. This may have had a strong influence on the limited number of high quality studies.

Rahul Rao, MBBS, MRCPsych, MD South London and Maudsley NHS Trust/ GKT Medical School, London, UK

1 Rao R. Cerebrovascular disease and late life depression: an age old association revisited. Int J Geriatr Psychiatry 2000;15:419-33.

2 Pickle LW, Mungiole M, Gillum RF. Geographic variation in stroke mortality in blacks and whites in the United States. Stroke 1997;28:1639-47. 